\title{
EFFECTS OF WOOD FLOUR ON THE MECHANICAL, THERMAL AND MORPHOLOGICAL PROPERTIES OF PÖLY (L-LACTIC ACID)-CHITOSAN BIOPOLYMER COMPOSITES
}

\author{
Ertugrul Altuntas ${ }^{1}$, Deniz Aydemir ${ }^{2,4}$
}

\begin{abstract}
The aim of this paper was to investigate the effects of wood flour on the mechanical, morphological and thermal properties of poly (L-lactic acid) (PLA)-chitosan biopolymer composites produced by compression molding. The composites were characterized by a combination of mechanical properties, scanning electron microscopy (SEM), thermogravimetric analysis (TGA), and differential scanning calorimetry (DSC). The addition of chitosan to PLA matrix reduced the tensile strength from 57,1 MPa for pure PLA to 34,3 MPa for $5 \%$ chitosan and $11,5 \mathrm{MPa}$ for $10 \%$ chitosan, and the flexure strength from $72,3 \mathrm{MPa}$ for pure PLLA to 30,4 MPa for 5\% chitosan and 24,6 MPa for 10\% chitosan. The change trend in the young's modulus was found to be similar as compare with the tensile strength. However, the flexure modulus generally increased with the addition of the chitosan as comparison with pure PLA. The mechanical properties of the PLA-chitosan blends with wood flour were found to be lower than theirs of the pure PLA. According to SEM images, some holes and small voids at various diameters on the fractured section of the all composites were seen. $\mathrm{T}_{\text {onset }}, \mathrm{T}_{10 \%}, \mathrm{~T}_{50 \%}$, $\mathrm{T}_{85 \%}$ of the pure PLA decreased with the addition of both chitosan and wood flour. Thermal stability of the PLA-chitosan blends was determined to be better than the PLA-chitosan composites with wood flour.
\end{abstract}

Keywords: Bio-based composites, DSC analysis, mechanical properties, Pinus sylvestris, TGA analysis, wood flour.

\section{INTRODUCTION}

In recent years, polylactic acid (PLA) has gained interest due to being made from renewable resources and biodegradability and an alternative to petroleum-based polymers. The concern of non-biodegradable polymers is its end of life use. Therefore, biodegradable biopolymers such as polylactic acid (PLA), polyhydroxybutyrate (PHB), polycaprolactone (PCL) can be an alternative solution for environmental problems (Abdelwahab et al. 2012, Ebadi-dehaghani et al. 2016). PLA is produced either by the polycondensation of lactic acid or by the ring opening polymerization of lactide. Lactide obtained from the fermentation of renewable sugar source, such as corn or sugar beets is a cyclic dimmer prepared by depolymerization of lactic acid (Rhim et al. 2009). PLA has received great interest due to its high mechanical properties, biodegradability and biocompatibility (Garlotta 2001, Wu and $\mathrm{Wu} 2006$ ). In the early stages of biopolymers, commercial biopolymers were used in limited areas, such as preparation of medical devices (bone surgery, suture, and chemotherapy, etc.) due to high production costs. As production cost of PLA has been lowered by new technologies, applications and large-scale production. Usage area of PLA has been extended to other commodity areas such as packaging, textiles and composite materials (Drumright et al. 2000). PLA applications have a significant potential for the commercial packaging industry duo to stiff films of high transparency and can be processed using readily available production technologies. However, brittleness and other properties such as low thermal stability,

\footnotetext{
${ }^{1}$ Department of Forest Industrial Engineering, Faculty of Forestry, Kahramanmaras Sutcu Imam University, Kahramanmaras, Turkey. ${ }^{2}$ Department of Forest Industrial Engineering, Faculty of Forestry, Bartin University, Bartin, Turkey.

•Corresponding author: denizaydemir@bartin.edu.tr

Received: 13.10.2017 Accepted: 19.08.2019
} 
medium gas barrier properties and low solvent resistance of the pure polymer limit its food packaging applications (Petersen et al. 2001). Moreover, thermal properties, toughness, water vapor and gas barrier properties of PLA are lower to those of classical petroleum-based polymers (Maazouz et al. 2011). To overcome these drawbacks, many approaches have been established, including copolymerization, compounding with nanofillers and blending with other polymers (Ying et al. 2007, Fukushima et al. 2009, Wu et al. 2006). Many studies have focused on blending PLA with other biopolymers (chitosan, starch, PHBV, PBAT, PHB) (Wu et al. 2006, Zhao et al. 2013, Abdelwahab et al. 2012, Armentano et al. 2015).

Chitin, one of the biopolymers is a polysaccharide made up of N-acetyl-glucosamine and N-glucosamine units. When the N-acetyl-glucosamine units are more than $50 \%$, the biopolymer is called chitin (Khor and Lim 2003). Chitosan is a linear cationic polysaccharide obtained by deacetylation of chitin derived from crustaceans such as crabs and shrimp. Since chitosan is a non-toxic, biocompatible and cost-effective material, this polymer is mainly used for biomedical and agricultural purposes (Sinha et al. 2004). Chitosan is known to interact with cells and cellular lysozyme degrades chitosan in-vivo (Tomihata and Ikada 1997).

The aim of this study was to investigate the effects of wood flour as reinforcing filler on the mechanical, thermal and morphology properties of polylactic acid (PLA)-chitosan blends.

\section{MATERIALS AND METHODS}

\section{Materials}

Poly L-lactic acid (PLLA) was supplied by Good Fellow, England. Density of PLLA has $1,24 \mathrm{~g} / \mathrm{cm}^{3}$. Chitosan (CAS: 9012-76-4) having properties such as average Mn 5000, wt 310000-375000 Da, 60\% oligosaccharide and $>75 \%$ deacetylation was obtained from Sigma-Aldrich (Germany). Wood flour was prepared with grinding of Scots Pine (Pinus sylvestris L.) which was supplied from a local mill. All materials were stored in sealed containers after being oven dried to 24 hours at $103 \pm 2{ }^{\circ} \mathrm{C}$ for wood flour, at $50^{\circ} \mathrm{C}$ for polylactic acid (PLA) and chitosan. The scots pine wood composes of $71,4 \%$ carbohydrates; $27,6 \%$ lignin; $0,4 \%$ ash, and $06 \%$ extractives (Kilic et al. 2010). Chitosan composes of $\beta$ - $(1 \rightarrow 4)$-linked D-glucosamine and N-acetyl-D-glucosamine (Das and Patra 2017).

\section{Compounding}

Biopolymers and wood flour were blended with speed mixer and then the blends were compounded using a twin screw extruder with $16 \mathrm{~mm}$ screw diameter and L/D ratio of 20 (Aysa Instruments, Turkey). Rotor speed and process temperature was set at $65 \mathrm{rpm}$ and $165^{\circ} \mathrm{C}$, respectively. The extruded blends were passed across a water bath and they was pelletized. The extruded blends were ground in a grinder (Aysa Instruments, Turkey), and then the pellets dried to 24 hours before compression molding. The temperature used for compressing molding, the compression pressure and pressure duration was $175^{\circ} \mathrm{C}, 25$ bars, and 5 min, respectively. Three panels with dimension of $20 \times 20 \times 3 \mathrm{~mm}^{3}$ for each formulation were produced with the compression molding, and mechanical test samples were obtained with cutting of the panels according to the related standards in the characterization section. The mechanical samples were prepared with sizing of the panels by a saw cutter. Ten replicates for the mechanical testing of all formulation were prepared. Experimental design of the PLA-chitosan blends and their composites with wood flour is shown in Table 1.

Table 1: Experimental design of the PLA-chitosan blends and their composites with wood flour.

\begin{tabular}{|l|c|c|c|}
\hline & Polylactic acid-PLA (\%) & Chitosan (\%) & Wood Flour (\%) \\
\hline Neat PLA & 100 & 0 & \\
\hline PLA5 & 95 & 5 & \\
\hline PLA10 & 90 & 10 & \\
\hline PLA5-10\% & 85,5 & 4,5 & 10 \\
\hline PLA5-20\% & 76 & 4 & 20 \\
\hline PLA10-10\% & 81 & 9 & 10 \\
\hline PLA10-20\% & 72 & 8 & 20 \\
\hline
\end{tabular}




\section{Characterization}

The tension tests were conducted according to the American Society of Testing and Materials (ASTM) standard D 638-14. All the tension tests were done at a rate of $0,5 \mathrm{~cm} / \mathrm{min}$. The flexure tests were conducted according to ASTM D 790-17, Test Method 1, Procedure A, i.e. three-point loading system. The tests were run at a test speed of $1,27 \mathrm{~mm} / \mathrm{min}$. The impact tests were conducted according to ASTM D 256-10. A mechanical tester with $5 \mathrm{kN}$ loading capacity (Zwick, Austria) was used to the mechanical testing. The results obtained were presented as an average for tested samples.

TGA was tested using Hitachi STA 7300 analyzer with a heating rate of $10^{\circ} \mathrm{C} / \mathrm{min}$ from room temperature to $600^{\circ} \mathrm{C}$, under nitrogen with a flow rate $20 \mathrm{ml} / \mathrm{min}$ to avoid sample oxidation.

DSC analysis of the samples was performed using a Perkin Elmer 6000 analyzer on samples of about $5 \mathrm{mg}$. For all specimens, testing was adopted heat/cool methods. All samples were heated to $25^{\circ} \mathrm{C}$ to $300^{\circ} \mathrm{C}$ at a ramp rate $10^{\circ} \mathrm{C} / \mathrm{min}$ and cooled with same ramp. Melting temperature $\left(T_{m}\right)$, crystallization temperature $\left(T_{c}\right)$, glass transition temperature $\left(T_{g}\right)$, glass transition enthalpy $\left(\Delta \mathrm{H}_{g}\right)$, melting enthalpy $\left(\Delta \mathrm{H}_{m}\right)$, crystallization enthalpy $\left(\Delta \mathrm{H}_{c}\right)$, crystallinity $\left(X_{c}\right)$ of the materials was determined from thermograms.

The samples were observed with an environmental scanning electron microscopy (ESEM), the Tescan MAIA3 XMU-SEM at an acceleration voltage of $5 \mathrm{kV}$. All samples surface was sputter-coated with gold using a Denton sputter coater for enhanced conductivity.

For the tensile and flexural strength, tensile and flexural modulus of elasticity and impact strength values, all multiple comparisons were first subjected to an analysis of variance (ANOVA) at the $99 \%$ confidence level, and significant differences between mean values of the samples were determined using Duncan's multiple range test. The significant differences between the samples were shown with letters, such as A, B, C, and D.

\section{RESULTS AND DISCUSSION}

\section{Mechanical properties}

The effects of wood flour on the mechanical properties of polylactic acid-chitosan biopolymer blends were investigated, and according to the obtained results (one-way ANOVA and Duncan test), the changes in both in groups and among the groups were found to be statistically significant. Table 2 shows mechanical properties such as tensile strength, young's modulus, flexure strength, flexure modulus, and izod impact strength of the all composites. The addition of chitosan to PLA matrix reduced the tensile strength from 57,1 MPa for neat PLA to $34,3 \mathrm{MPa}$ for $5 \%$ chitosan and $11,5 \mathrm{MPa}$ for $10 \%$ chitosan, and the flexure strength from $72,3 \mathrm{MPa}$ to 30,4 MPa for 5\% chitosan, 24,6 MPa for 10\% chitosan. Therefore; it can be said that chitosan has to be a negative effect on the mechanical properties of neat PLA. The addition of wood flour was found to generally decrease the mechanical properties of PLA-chitosan blends. When loadings of wood flour were raised from $10 \%$ to $20 \%$, the tensile strength of chitosan-PLA blends increased to the composites with both $5 \%$ and $10 \%$ chitosan. However; both the tensile strength of all the PLA-chitosan composites with wood flour were found to be lower as comparison with neat PLA. The change trend in the young's modulus was found to be similar as compare with the tensile strength expect for $10 \%$ chitosan-PLA blends with $20 \%$ wood flour. The young's modulus of $10 \%$ chitosan-PLA biopolymer composites increased as 3,3\% with $20 \%$ wood flour, and the young's modulus of the other all composites decreased, and the largest decrease ratio was found to be $22,6 \%$. As results, the addition of the chitosan effected more the tensile strength as compare with young's modulus. 
Table 2: Mechanical properties of the PLA-chitosan composites.

\begin{tabular}{|l|c|c|c|c|c|}
\hline Compositions & $\begin{array}{c}\text { Tensile } \\
\text { Strength } \\
\text { (MPa) }\end{array}$ & $\begin{array}{c}\text { Young's } \\
\text { modulus } \\
\mathbf{( M P a )}\end{array}$ & $\begin{array}{c}\text { Flexure } \\
\text { Strength } \\
\mathbf{( M P a )}\end{array}$ & $\begin{array}{c}\text { Flexure } \\
\text { Modulus } \\
\mathbf{( G P a )}\end{array}$ & $\begin{array}{c}\text { Izod } \\
\text { Impact } \\
\text { Strength } \\
\left(\mathbf{k J} / \mathbf{m}^{2}\right)\end{array}$ \\
\hline Neat PLA & $57,1 \mathrm{~A}$ & $1,5 \mathrm{CD}$ & $72,3 \mathrm{C}$ & $3,1 \mathrm{~A}$ & $2,8 \mathrm{D}$ \\
\hline PLA5 & $34,3 \mathrm{~B}$ & $1,4 \mathrm{BCD}$ & $30,4 \mathrm{C}$ & $3,3 \mathrm{~A}$ & $2,5 \mathrm{C}$ \\
\hline PLA5-10\% & $13,9 \mathrm{~F}$ & $1,3 \mathrm{~A}$ & $16,4 \mathrm{~A}$ & $3,2 \mathrm{~A}$ & $2,3 \mathrm{C}$ \\
\hline PLA5-20\% & $19,7 \mathrm{EF}$ & $1,4 \mathrm{~B}$ & $20,8 \mathrm{~B}$ & $3,5 \mathrm{~B}$ & $1,3 \mathrm{~B}$ \\
\hline PLA10 & $11,5 \mathrm{C}$ & $1,1 \mathrm{BCD}$ & $24,6 \mathrm{~B}$ & $4,4 \mathrm{C}$ & $1,2 \mathrm{~B}$ \\
\hline PLA10-10\% & $15,9 \mathrm{DE}$ & $1,4 \mathrm{BC}$ & $21,8 \mathrm{~B}$ & $3,9 \mathrm{~B}$ & $1,3 \mathrm{~B}$ \\
\hline PLA10-20\% & $17 \mathrm{CD}$ & $1,5 \mathrm{D}$ & $23,6 \mathrm{~B}$ & $4,4 \mathrm{C}$ & $1,0 \mathrm{~A}$ \\
\hline
\end{tabular}

As seen to Table 2, the flexure strength values of the neat PLA (72,3 MPa) decreased with the addition of the chitosan to $30,4 \mathrm{MPa}$ for $5 \%$ chitosan and $24,6 \mathrm{MPa}$ for $10 \%$ chitosan. When the loading of the chitosan to PLA matrix raised, the flexure strength was found to decrease more. The addition of wood flour to PLA-chitosan blends also decreased to the flexure strength of PLA-chitosan blends for both $10 \%$ and $20 \%$ loadings. The change trend in the flexure modulus value of the PLA-chitosan composites was found to be not similar as compare with young's modulus/tensile strength and flexure strength. Because the addition of the chitosan increased at 7,5\% for 5\% chitosan and $42,3 \%$ for $10 \%$ chitosan the flexure modulus of the all PLA-chitosan blends. The addition of the wood flour to the chitosan-PLA blends provided an improvement on the flexure modulus of the PLA-chitosan blends as comparison with pure PLA. Although the addition of the chitosan generally decreased the flexure strength, the addition of the chitosan and wood flour increased the flexure modulus of the all PLA-chitosan composites. The izod impact strength values of the PLA-chitosan composites were given in Table 2.

The addition of the chitosan decreased to $10.7 \%$ for $5 \%$ chitosan and $57,1 \%$ for $10 \%$ chitosan to the izod IS of the all PLA-chitosan composites. The izod IS of the chitosan-PLA blends generally decreased with the loading of wood flour. The maximum decrease in the izod IS was found at $54,2 \%$ for $10 \%$ chitosan-PLA with $20 \%$ wood flour. An incompatibility between chitosan and PLA was reported by Suyatma et al. (2003). Therefore, it can be said that the addition of the chitosan decreased all the mechanical properties such as young's modulus, tensile strength, flexure strength except for flexure modulus. In this study, the wood flour was found to provide some improvements on the mechanical properties of the PLA-chitosan blends. In another study, the addition of wood flour to the PLA matrix was determined to increase the mechanical properties of the PLA composites (Shah et al. 2008). In a similar study, the addition of chitosan was raised from $0 \%$ to $30 \%$, tensile strength of PLA-chitosan blends was found to decrease. The decrease of the tensile strength with increasing content of chitosan was found to provide an increase in young's modulus (Quiroz-Castillo et al. 2015).

\section{Scanning electron microscopy (SEM)}

SEM images of the PLA-chitosan composites for 5\% chitosan (a) and 10\% chitosan (b), and the blends with $10 \%$ wood flour (c), $20 \%$ wood flour (d) were given in Figure 1. 

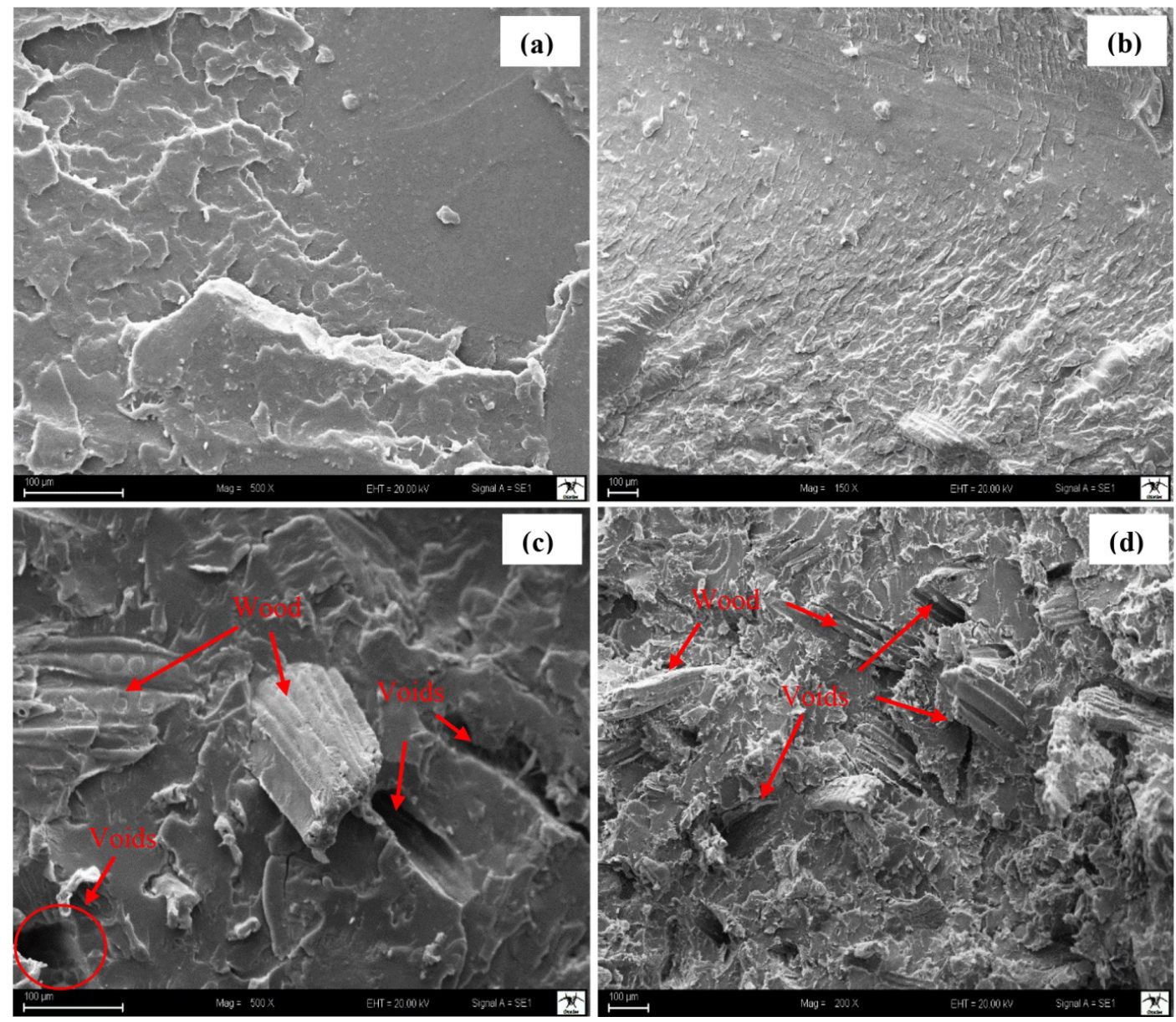

Figure 1: SEM images of the PLA-chitosan composites ((a): 5\% chitosan, (b): 10\% chitosan, (c): the blends with $10 \%$ wood flour, (d): the blends with $20 \%$ wood flour).

The blending was homogenously provided according to SEM images in Figure 1a and Figure 1b, and any voids in the inner structure of the chitosan-PLA blends cannot be determined. The morphological properties of the blends changed with addition of the wood flour, and some holes between wood flour and the matrix blends were found. In a study on the morphological properties of PLA-chitosan composites, it was found that the PLA-chitosan fractured surfaces were covered with fillers, and a number of micro voids and holes throughout the fractured surface. The fractured surface was also determined to be smooth and homogeneous surfaces upon incorporation of CS in the PLA matrix (Zakaria et al. 2013). The similar results were obtained by Shah et al. (2008).

\section{Thermogravimetric analysis (TGA/DTG)}

The TGA curves of the PLA-chitosan composites were given in Figure 2. Three stages of mass loss are associated with the TGA curve after heating from $25^{\circ} \mathrm{C}$ to $900^{\circ} \mathrm{C}$. The first stage, which is up to $250^{\circ} \mathrm{C}$, is usually associated with the release of moisture, humidity or other volatiles from the biopolymer. The second stage (up to about $500^{\circ} \mathrm{C}$ ) corresponds to volatilization stages of thermally degraded units and show relatively big DTG curve in Figure 2. The final third stage extends to the ending test temperature at $650{ }^{\circ} \mathrm{C}$ in association with more than 83,9 wt. $\%$ of loss for $5 \%$ chitosan-PLA blends with $20 \%$ wood flour. The results of $\mathrm{T}_{\text {onset }}, \mathrm{T}_{10 \%}$, $\mathrm{T}_{50 \%}, \mathrm{~T}_{85 \%}$ and mass loss at $600^{\circ} \mathrm{C}$ were listed in Table 2 . 


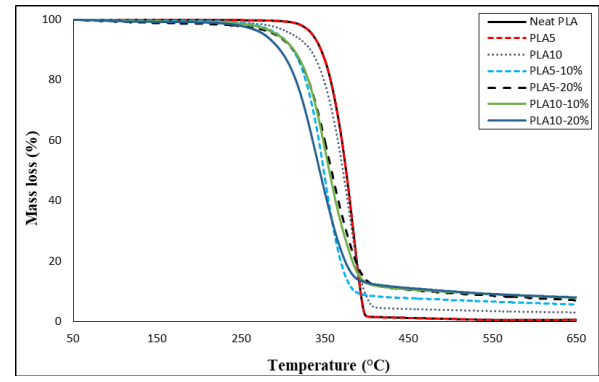

Figure 2: The TGA curves of the PLA-chitosan composites.

As seen as Table 3, $\mathrm{T}_{\text {onset }}, \mathrm{T}_{10 \%}, \mathrm{~T}_{50 \%}, \mathrm{~T}_{85 \%}$ of the PLA-chitosan composites decreased with the addition of both chitosan and wood flour. Thermal stability of the biopolymer blends was determined to be better than the PLA-chitosan composites with wood flour. The maximum and minimum temperature for $\mathrm{T}_{50 \%}$ were determined as $344^{\circ} \mathrm{C}$ for $10 \%$ chitosan-PLA blends with $20 \%$ wood flour and $376^{\circ} \mathrm{C}$ for neat PLA, respectively. The mass loss of the PLA-chitosan composites was found to decrease from $99 \%$ for neat PLA to $84 \%$ for $5 \%$ chitosan-PLA blends with $20 \%$ wood flour. The thermal decomposition temperature $\left(\mathrm{T}_{\text {onset }}, \mathrm{T}_{10 \%}, \mathrm{~T}_{50 \%}\right.$, $\mathrm{T}_{85 \%}$ ) and mass losses of the PLA-chitosan blends were found to be lower than the neat PLA matrix. As a result, it can be said that both chitosan and wood flour decreased the thermal stability of the neat PLA. In a study, Bonilla et al. (2015) found that the incorporation of chitosan did not promote significant changes in the thermal behavior of neat PLA. The similar results were obtained by Quiroz-Castillo et al. (2015).

Table 3: The summary of TGA curves of PLA-chitosan composites.

\begin{tabular}{|l|c|c|c|c|c|}
\hline Composites & $\mathbf{T}_{\text {onset }}\left({ }^{\circ} \mathbf{C}\right)$ & $\mathbf{T}_{\mathbf{1 0 \%}}\left({ }^{\circ} \mathbf{C}\right)$ & $\mathbf{T}_{\mathbf{5 0 \%}}\left({ }^{\circ} \mathbf{C}\right)$ & $\mathbf{T}_{\mathbf{8 5 \%}}\left({ }^{\circ} \mathbf{C}\right)$ & $\begin{array}{c}\text { Mass loss } \\
(\mathbf{\%})\end{array}$ \\
\hline Neat PLA & 355 & 347 & 376 & 391 & 99 \\
\hline PLA5 & 336 & 346 & 375 & 390 & 95 \\
\hline PLA10 & 347 & 332 & 371 & 392 & 92 \\
\hline PLA5-10\% & 331 & 311 & 348 & 374 & 88 \\
\hline PLA5-20\% & 322 & 312 & 358 & 395 & 84 \\
\hline PLA10-10\% & 326 & 313 & 355 & 391 & 86 \\
\hline PLA10-20\% & 313 & 296 & 344 & 385 & 93 \\
\hline
\end{tabular}

\section{Differential scanning calorimetry (DSC)}

$T_{g}, T_{m}, T_{c}, X_{c}$ and the enthalpies of the PLA-chitosan composites were given in Table 4. DSC analysis was conducted with cooling and heating of the neat biopolymers and the PLA-chitosan composites. $T_{g}, T_{c}$ and $T_{m}$ changed with the loadings of the chitosan and wood flour. The highest value of $\mathrm{T}_{\mathrm{g}}$ was found as $58^{\circ} \mathrm{C}$ for neat PLA, and $55^{\circ} \mathrm{C}$ for $10 \%$ chitosan-PLA biopolymer blends. $\mathrm{T}_{\mathrm{g}}$ decreased with the addition of the wood flour. Both $\mathrm{T}_{\mathrm{m}}$ and $\mathrm{T}_{\mathrm{c}}$ decreased with chitosan and wood flour. The maximum and minimum temperature value in the $\mathrm{T}_{\mathrm{m}}$ and $\mathrm{T}_{\mathrm{c}}$ of the PLA-chitosan composites were determined as $147^{\circ} \mathrm{C}$ for $5 \%$ chitosan-PLA blends and $119^{\circ} \mathrm{C}$ for $10 \%$ chitosan-PLA blends with $20 \%$ wood flour, and $134^{\circ} \mathrm{C}$ for $5 \%$ chitosan-PLA blends with $10 \%$ wood flour and $108^{\circ} \mathrm{C}$ for $5 \%$ chitosan-PLA blends. $\mathrm{X}$ values of the PLA-chitosan composites increased with the addition of the chitosan, and the maximum $X_{c}$ was found as $35 \%$ for $10 \%$ chitosan-PLA blends. However, the addition of the wood flour to biopolymer blend matrix was determined to decrease the $\mathrm{X}_{c}$ of the PLA-chitosan composites with wood flour. The maximum and minimum $\mathrm{X}_{\mathrm{c}}$ of the PLA-chitosan composites was measured as $26 \%$ for $10 \%$ chitosan-PLA blends with $20 \%$ wood flour and $20 \%$ for $5 \%$ chitosan-PLA blends with $20 \%$ wood flour. In a study conducted on the thermal properties of chitosan-polylactic acid, it was found that the increase of the chitosan addition in the composite films caused to a decrease in the $\mathrm{T}_{\mathrm{g}}$ values. The decreasing in $\mathrm{T}_{\mathrm{g}}$ values was found to be due to additional action of chitosan - most probably the increased hydrophilicity of the composite films causes higher amount of bound water, which acts as a plasticizer (Marudova et al. 2015, Bonilla et al. 2015, Quiroz-castillo et al. 2014). In another study, no significant effects of the chitosan addition on the $\mathrm{T}_{\mathrm{g}}$ and $\mathrm{T}_{\mathrm{m}}$ values was observed, which can be due to the lack of miscibility of both polymers. However; crystallization temperature $\left(\mathrm{T}_{\mathrm{c}}\right.$ ) of the composites significantly increased with the addition of chitosan particles (Bonilla et al. 2015). 
Table 4: The summary of DSC results of PLA-chitosan composites.

\begin{tabular}{|l|c|c|c|c|c|}
\hline Composites & $\mathbf{T}_{\mathbf{g}}\left({ }^{\circ} \mathbf{C}\right)$ & $\mathbf{T}_{\mathbf{m}}\left({ }^{\circ} \mathbf{C}\right)$ & $\mathbf{\Delta H}_{\mathbf{m}}(\mathbf{J} / \mathbf{g})$ & $\mathbf{T}_{\mathbf{c}}\left({ }^{\circ} \mathbf{C}\right)$ & $\mathbf{X}_{\mathbf{c}}(\mathbf{\%})$ \\
\hline Neat PLA & 58 & 150 & 22 & 127 & 24 \\
\hline PLA5 & 53 & 147 & 29 & 108 & 33 \\
\hline PLA10 & 55 & 139 & 30 & 115 & 35 \\
\hline PLA5-10\% & 53 & 134 & 20 & 116 & 24 \\
\hline PLA5-20\% & 50 & 138 & 15 & 119 & 20 \\
\hline PLA10-10\% & 50 & 138 & 21 & 116 & 25 \\
\hline PLA10-20\% & 54 & 137 & 19 & 119 & 26 \\
\hline
\end{tabular}

\section{CONCLUSIONS}

Chitosan was efficiently blended with PLA matrices by extrusion in 5\% and $10 \%$ of the biopolymer matrix. The addition of wood flour to PLA-chitosan blends were added with the addition of $10 \%$ and $20 \%$. The presence of chitosan decreased the all mechanical properties such as tensile strength, young's modulus, flexure strength and izod impact strength except for flexure modulus. In the fractured surfaces of PLA-chitosan blends, some micro voids and holes between polymer matrix and fillers were determined. TGA analysis showed that the addition of both chitosan and wood flour were decreased the thermal stability of the pure PLA. According DSC analysis, Tg, Tc and Tm of the PLA-chitosan composites were found to be lower than neat PLA. As a result, the addition of chitosan can be said to have a negative effect on the mechanical and thermal properties of the PLA and the wood flour provided some improvements on the all mechanical and thermal properties of PLA-chitosan composites. New studies should be conducted to find the effects of the chitosan on blending of chitosan with polylactic acid and the reinforcing of wood flour of their blends.

\section{REFERENCES}

Abdelwahab, M.A.; Flynn, A.; Chiou, B.S.; Imam, S.; Orts, W.; Chiellini, E. 2012. Thermal, mechanical and morphological characterization of plasticized PLA-PHB blends. Polymer Degradation and Stability 97(9): 1822-1828.

ASTM International. 2014. Standard Test Method for Tensile Properties of Plastics. ASTM D 638-14. 2014. ASTM International: West Conshohocken, PA.

ASTM International. 2017. Standard Test Methods for Flexural Properties of Unreinforced and Reinforced Plastics and Electrical Insulating Material. ASTM D 790-17. 2017. ASTM International: West Conshohocken, PA.

ASTM International. 2018. Standard Test Methods for Determining the Izod Pendulum Impact Resistance of Plastics. ASTM D 256-10. 2018. ASTM International: West Conshohocken, PA.

Armentano, I.; Fortunati, E.; Burgos, N.; Dominici, F.; Luzi, F.; Fiori, S.; Jiménez, A.; Yoon, K.; Ahn, J.; Kang, S.; Kenny, J. M. 2015. Processing and characterization of plasticized PLA/PHB blends for biodegradable multiphase systems. Express Polym Lett 9 (7): 583-596.

Bonilla, J.; Fortunati, E.; Vargas, M.; Chiralt, A.; Kenny, J.M. 2015. Effects of chitosan on the physicochemical and antimicrobial properties of PLA films. Journal of Food Engineering 119 (2): 236-243.

Das, B.; Patra, S. 2017. Antimicrobials: Meeting the Challenges of Antibiotic Resistance Through Nanotechnology. In Nanostructures for Antimicrobial Therapy, Chapter 1, Ed. Ficai, A.; Grumezesc, A. M., ISBN 978-0-323-46152-8, pp. 1-22. Elsevier Inc. https://www.sciencedirect.com/science/article/pii/ B9780323461528000019.

Drumright, R.E., Gruber, P.R.; Henton, D.E. 2000. Polylactic acid technology. Advanced Materials 12(23): 1841-1846.

Ebadi-Dehaghani, H.; Khonakdar, H.A.; Barikani, M.; Jafari, S.H.; Wagenknecht, U.; Heinrich, G. 2016. On Localization of Clay Nanoparticles in Polypropylene/poly (lactic acid) Blend Nanocomposites: Correlation with Mechanical Properties. Journal of Macromolecular Science Part B-Physics 55(4): 344-360.

Fukushima, K.; Abbate, C.; Tabuani, D.; Gennari, M.; Camino, G. 2009. Biodegradation of poly (lac- 
tic acid) and its nanocomposites. Polym Degrad Stab 94 (10): 1646-1655.

Garlotta, D. 2001. A literature review of poly (lactic acid). Journal of Polymers and the Environment 9(2): 63-84.

Kilic, A.; Sariusta, S.E.; Hafizoğlu, H. 2010. Sarıçam, Karaçam ve Kızılçam basınç odununun kimyasal yapıs1. Bartın Orman Fakültesi Dergisi 12(18): 33-39. 2349.

Khor, E.; Lim, L.Y. 2003. Implantable applications of chitin and chitosan. Biomaterials 24(13): 2339-

Maazouz, A.; Lamnawar, K.; Mallet, B. 2011. Compounding and processing of biodegradable materials based on PLA for packaging applications: In greening the $21^{\text {st }}$ century materials world. Front Sci Eng 1: 1-44.

Marudova, M.; Delcheva, E.; Zsivanovits, G. 2015. Mechanical properties of composite films based on chitosan and poly (1-lactic acid). Bulgarian Chemical Communications 47:127-134.

Petersen, K.; Nielsen, P.V.; Olsen, M.B. 2001. Physical and mechanical properties of biobased materials - Starch polylactate and polyhydroxybutyrate. Starch-Starke 53(8): 356-361.

Quiroz-Castillo, J.M.; Rodríguez-Félix, D.E.; Grijalva-Monteverde, H.; Del Castillo-Castro, T.; Plascencia-Jatomea, M.; Rodríguez-Félix, F.; Herrera-Franco, P.J. 2014. Preparation of extruded polyethylene/chitosan blends compatibilized with polyethylene-graft-maleic anhydride. J Carbohydr Polym 101: 1094-1100.

Quiroz-Castillo, J.M.; Rodríguez-Félix, D.E.; Grijalva-Monteverde, H.; Lizárraga-Laborín, L.L.; Castillo-Ortega, M.M.; Del Castillo-Castro, T.; Herrera-Franco, P.J. 2015. Preparation and characterization of films extruded of polyethylene/chitosan modified with poly (lactic acid). Materials 8(1): 137-148.

Rhim, J.W.; Hong, S.I.; Ha, C.S. 2009. Tensile, water vapor barrier and antimicrobial properties of PLA/ nanoclay composite films. Lwt-Food Science and Technology 42(2): 612-617.

Shah, B.; Selke, S.E.; Walters, M.B.; Heiden, P.A. 2008. Effects of Wood Flour and Chitosan on Mechanical, Chemical, and Thermal Properties of Polylactide. Polymer Composites 29 (6): 655-663.

Sinha, V.R.; Singla, A.K.; Wadhawan, S.; Kaushik, R.; Kumria, R.; Bansal, K.; Dhawan, S. 2004. Chitosan microspheres as a potential carrier for drugs. International Journal of Pharmaceutics 274(1-2): 1-33.

Suyatma, N.E.; Copinet, A.; Tighzert, L.; Coma, V. 2003. Mechanical and Barrier Properties of Biodegradable Films Made from Chitosan and Poly (lactic acid) Blends. J Polym Environ 12 (1): 1-6.

Tomihata, K.; Ikada, Y. 1997. In vitro and in vivo degradation of films of chitin and its deacetylated derivatives. Biomaterials 18(7): 567-575.

Wu, D.; Wu, L.; Zhang, M. 2006. Rheology and thermal stability of polylactide/clay nanocomposites. Polym Degrad Stab 91 (12): 3149-3155.

Wu, T.M.; Wu, C.Y. 2006. Biodegradable poly (lactic acid)/chitosan-modified montmorillonite nanocomposites: Preparation and characterization. Polym Degrad Stab 91 (9): 2198-2204.

Ying, L.; Kun-Yu, Z.; Zhong-Min, D.; Li-Song, D.; Yue-Sheng, L. 2007. Study of hydrogen-bonded blend of polylactide with biodegradable hyperbranched poly (ester amide). Macromolecules 40 (17): 62576267.

Zakaria, Z.; Islam, M.S.; Hassan, A.; Mohamad Haafiz, M.K.; Arjmandi, R.; Inuwa, I.M.; Hasan, M. 2013. Mechanical properties and morphological characterization of PLA/chitosan/epoxidized natural rubber composites. Advances in Materials Science and Engineering Article ID 629092 (2013): 1-7.

Zhao, H.; Cui, Z.; Wang, X.; Turng, L.S.; Peng, Z. 2013. Processing and characterization of solid and microcellular poly(lactic acid)/polyhydroxybutyrate-Valerates (PLA/PHBV) blends and PLA/PHBV/Clay nanocomposites. Compos Part B 51: 79-91. 